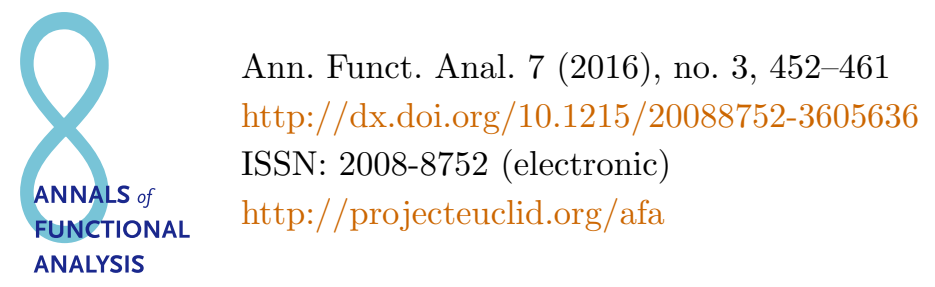

\title{
SCHÄFFER-TYPE CONSTANT AND UNIFORM NORMAL STRUCTURE IN BANACH SPACES
}

\author{
ZHAN-FEI ZUO ${ }^{1,2}$ and CHUN-LEI TANG ${ }^{1 *}$
}

Communicated by P. N. Dowling

\begin{abstract}
The exact value of the Schäffer-type constants are investigated under the absolute normalized norms on $\mathbb{R}^{2}$ by means of their corresponding continuous convex functions on $[0,1]$. Moreover, some sufficient conditions which imply uniform normal structure are presented. These results improve some known results.
\end{abstract}

\section{INTRODUCTION AND PRELIMINARIES}

Throughout this article, $S_{X}$ and $B_{X}$ denote the unit sphere and the unit ball of a Banach space $X$, respectively. Let $C$ be a nonempty bounded closed convex subset of a Banach space $X$. A mapping $T: C \rightarrow C$ is said to be nonexpansive, provided that the inequality

$$
\|T x-T y\| \leq\|x-y\|
$$

holds for every $x, y \in C$. A Banach space $X$ is said to have the fixed point property if every nonexpansive mapping $T: C \rightarrow C$ has a fixed point.

Recall that a Banach space $X$ is called uniformly nonsquare in the sense of Schäffer if there is a $\lambda>1$ such that

$$
\max (\|x+y\|,\|x-y\|) \geq \lambda
$$

for all $x, y \in S_{X}$. The Schäffer constant, defined by

$$
S(X)=\inf \left\{\max \left\{\|x+y\|,\|x-y\|: x, y \in S_{X}\right\}\right\},
$$

Copyright 2016 by the Tusi Mathematical Research Group.

Received Oct. 13, 2015; Accepted Jan. 25, 2016.

${ }^{*}$ Corresponding author.

2010 Mathematics Subject Classification. Primary 46B20; Secondary 46B99.

Keywords. Schäffer-type constant, absolute normalized norm, uniform normal structure. 


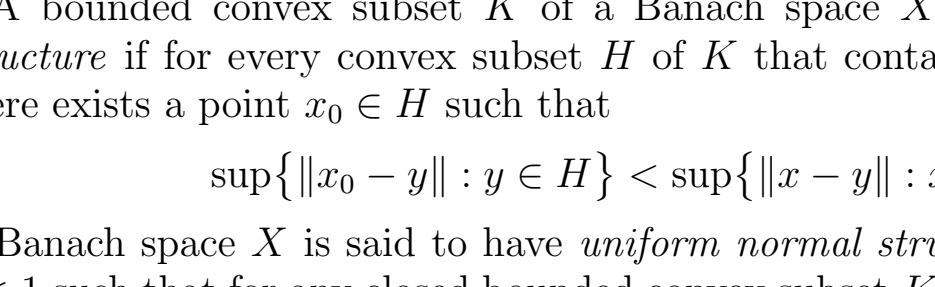

\title{
SCHÄFFER-TYPE CONSTANT AND UNIFORM NORMAL STRUCTURE IN BANACH SPACES
}

\author{
ZHAN-FEI ZUO ${ }^{1,2}$ and CHUN-LEI TANG ${ }^{1 *}$
}

Communicated by P. N. Dowling

\begin{abstract}
The exact value of the Schäffer-type constants are investigated under the absolute normalized norms on $\mathbb{R}^{2}$ by means of their corresponding continuous convex functions on $[0,1]$. Moreover, some sufficient conditions which imply uniform normal structure are presented. These results improve some known results.
\end{abstract}

\section{INTRODUCTION AND PRELIMINARIES}

Throughout this article, $S_{X}$ and $B_{X}$ denote the unit sphere and the unit ball of a Banach space $X$, respectively. Let $C$ be a nonempty bounded closed convex subset of a Banach space $X$. A mapping $T: C \rightarrow C$ is said to be nonexpansive, provided that the inequality

$$
\|T x-T y\| \leq\|x-y\|
$$

holds for every $x, y \in C$. A Banach space $X$ is said to have the fixed point property if every nonexpansive mapping $T: C \rightarrow C$ has a fixed point.

Recall that a Banach space $X$ is called uniformly nonsquare in the sense of Schäffer if there is a $\lambda>1$ such that

$$
\max (\|x+y\|,\|x-y\|) \geq \lambda
$$

for all $x, y \in S_{X}$. The Schäffer constant, defined by

$$
S(X)=\inf \left\{\max \left\{\|x+y\|,\|x-y\|: x, y \in S_{X}\right\}\right\},
$$

Copyright 2016 by the Tusi Mathematical Research Group.

Received Oct. 13, 2015; Accepted Jan. 25, 2016.

${ }^{*}$ Corresponding author.

2010 Mathematics Subject Classification. Primary 46B20; Secondary 46B99.

Keywords. Schäffer-type constant, absolute normalized norm, uniform normal structure. 


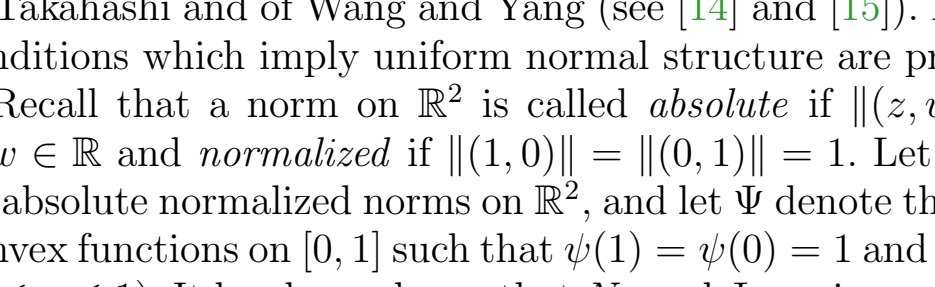

\title{
SCHÄFFER-TYPE CONSTANT AND UNIFORM NORMAL STRUCTURE IN BANACH SPACES
}

\author{
ZHAN-FEI ZUO ${ }^{1,2}$ and CHUN-LEI TANG ${ }^{1 *}$
}

Communicated by P. N. Dowling

\begin{abstract}
The exact value of the Schäffer-type constants are investigated under the absolute normalized norms on $\mathbb{R}^{2}$ by means of their corresponding continuous convex functions on $[0,1]$. Moreover, some sufficient conditions which imply uniform normal structure are presented. These results improve some known results.
\end{abstract}

\section{INTRODUCTION AND PRELIMINARIES}

Throughout this article, $S_{X}$ and $B_{X}$ denote the unit sphere and the unit ball of a Banach space $X$, respectively. Let $C$ be a nonempty bounded closed convex subset of a Banach space $X$. A mapping $T: C \rightarrow C$ is said to be nonexpansive, provided that the inequality

$$
\|T x-T y\| \leq\|x-y\|
$$

holds for every $x, y \in C$. A Banach space $X$ is said to have the fixed point property if every nonexpansive mapping $T: C \rightarrow C$ has a fixed point.

Recall that a Banach space $X$ is called uniformly nonsquare in the sense of Schäffer if there is a $\lambda>1$ such that

$$
\max (\|x+y\|,\|x-y\|) \geq \lambda
$$

for all $x, y \in S_{X}$. The Schäffer constant, defined by

$$
S(X)=\inf \left\{\max \left\{\|x+y\|,\|x-y\|: x, y \in S_{X}\right\}\right\},
$$

Copyright 2016 by the Tusi Mathematical Research Group.

Received Oct. 13, 2015; Accepted Jan. 25, 2016.

${ }^{*}$ Corresponding author.

2010 Mathematics Subject Classification. Primary 46B20; Secondary 46B99.

Keywords. Schäffer-type constant, absolute normalized norm, uniform normal structure. 


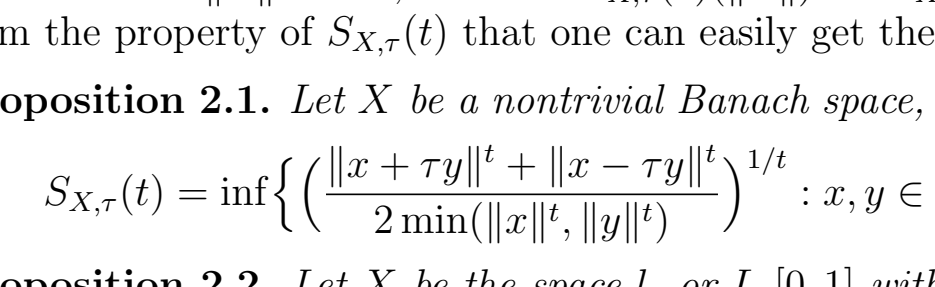

\title{
SCHÄFFER-TYPE CONSTANT AND UNIFORM NORMAL STRUCTURE IN BANACH SPACES
}

\author{
ZHAN-FEI ZUO ${ }^{1,2}$ and CHUN-LEI TANG ${ }^{1 *}$
}

Communicated by P. N. Dowling

\begin{abstract}
The exact value of the Schäffer-type constants are investigated under the absolute normalized norms on $\mathbb{R}^{2}$ by means of their corresponding continuous convex functions on $[0,1]$. Moreover, some sufficient conditions which imply uniform normal structure are presented. These results improve some known results.
\end{abstract}

\section{INTRODUCTION AND PRELIMINARIES}

Throughout this article, $S_{X}$ and $B_{X}$ denote the unit sphere and the unit ball of a Banach space $X$, respectively. Let $C$ be a nonempty bounded closed convex subset of a Banach space $X$. A mapping $T: C \rightarrow C$ is said to be nonexpansive, provided that the inequality

$$
\|T x-T y\| \leq\|x-y\|
$$

holds for every $x, y \in C$. A Banach space $X$ is said to have the fixed point property if every nonexpansive mapping $T: C \rightarrow C$ has a fixed point.

Recall that a Banach space $X$ is called uniformly nonsquare in the sense of Schäffer if there is a $\lambda>1$ such that

$$
\max (\|x+y\|,\|x-y\|) \geq \lambda
$$

for all $x, y \in S_{X}$. The Schäffer constant, defined by

$$
S(X)=\inf \left\{\max \left\{\|x+y\|,\|x-y\|: x, y \in S_{X}\right\}\right\},
$$

Copyright 2016 by the Tusi Mathematical Research Group.

Received Oct. 13, 2015; Accepted Jan. 25, 2016.

${ }^{*}$ Corresponding author.

2010 Mathematics Subject Classification. Primary 46B20; Secondary 46B99.

Keywords. Schäffer-type constant, absolute normalized norm, uniform normal structure. 


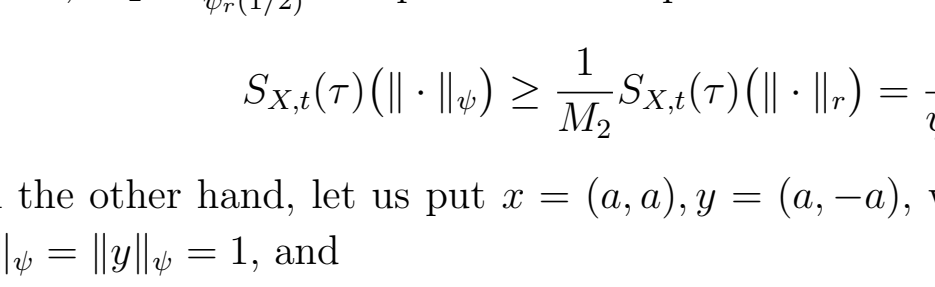

\title{
SCHÄFFER-TYPE CONSTANT AND UNIFORM NORMAL STRUCTURE IN BANACH SPACES
}

\author{
ZHAN-FEI ZUO ${ }^{1,2}$ and CHUN-LEI TANG ${ }^{1 *}$
}

Communicated by P. N. Dowling

\begin{abstract}
The exact value of the Schäffer-type constants are investigated under the absolute normalized norms on $\mathbb{R}^{2}$ by means of their corresponding continuous convex functions on $[0,1]$. Moreover, some sufficient conditions which imply uniform normal structure are presented. These results improve some known results.
\end{abstract}

\section{INTRODUCTION AND PRELIMINARIES}

Throughout this article, $S_{X}$ and $B_{X}$ denote the unit sphere and the unit ball of a Banach space $X$, respectively. Let $C$ be a nonempty bounded closed convex subset of a Banach space $X$. A mapping $T: C \rightarrow C$ is said to be nonexpansive, provided that the inequality

$$
\|T x-T y\| \leq\|x-y\|
$$

holds for every $x, y \in C$. A Banach space $X$ is said to have the fixed point property if every nonexpansive mapping $T: C \rightarrow C$ has a fixed point.

Recall that a Banach space $X$ is called uniformly nonsquare in the sense of Schäffer if there is a $\lambda>1$ such that

$$
\max (\|x+y\|,\|x-y\|) \geq \lambda
$$

for all $x, y \in S_{X}$. The Schäffer constant, defined by

$$
S(X)=\inf \left\{\max \left\{\|x+y\|,\|x-y\|: x, y \in S_{X}\right\}\right\},
$$

Copyright 2016 by the Tusi Mathematical Research Group.

Received Oct. 13, 2015; Accepted Jan. 25, 2016.

${ }^{*}$ Corresponding author.

2010 Mathematics Subject Classification. Primary 46B20; Secondary 46B99.

Keywords. Schäffer-type constant, absolute normalized norm, uniform normal structure. 


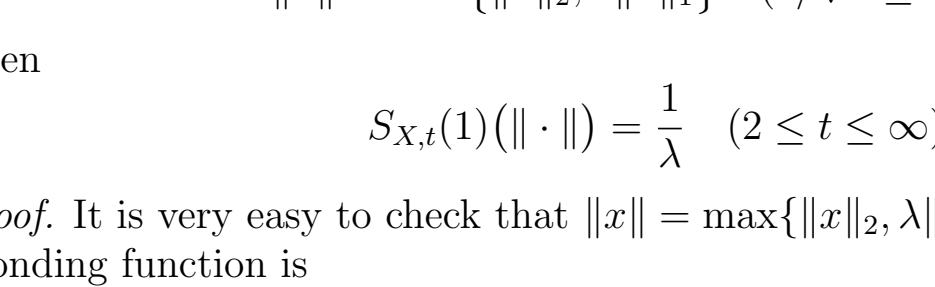

\title{
SCHÄFFER-TYPE CONSTANT AND UNIFORM NORMAL STRUCTURE IN BANACH SPACES
}

\author{
ZHAN-FEI ZUO ${ }^{1,2}$ and CHUN-LEI TANG ${ }^{1 *}$
}

Communicated by P. N. Dowling

\begin{abstract}
The exact value of the Schäffer-type constants are investigated under the absolute normalized norms on $\mathbb{R}^{2}$ by means of their corresponding continuous convex functions on $[0,1]$. Moreover, some sufficient conditions which imply uniform normal structure are presented. These results improve some known results.
\end{abstract}

\section{INTRODUCTION AND PRELIMINARIES}

Throughout this article, $S_{X}$ and $B_{X}$ denote the unit sphere and the unit ball of a Banach space $X$, respectively. Let $C$ be a nonempty bounded closed convex subset of a Banach space $X$. A mapping $T: C \rightarrow C$ is said to be nonexpansive, provided that the inequality

$$
\|T x-T y\| \leq\|x-y\|
$$

holds for every $x, y \in C$. A Banach space $X$ is said to have the fixed point property if every nonexpansive mapping $T: C \rightarrow C$ has a fixed point.

Recall that a Banach space $X$ is called uniformly nonsquare in the sense of Schäffer if there is a $\lambda>1$ such that

$$
\max (\|x+y\|,\|x-y\|) \geq \lambda
$$

for all $x, y \in S_{X}$. The Schäffer constant, defined by

$$
S(X)=\inf \left\{\max \left\{\|x+y\|,\|x-y\|: x, y \in S_{X}\right\}\right\},
$$

Copyright 2016 by the Tusi Mathematical Research Group.

Received Oct. 13, 2015; Accepted Jan. 25, 2016.

${ }^{*}$ Corresponding author.

2010 Mathematics Subject Classification. Primary 46B20; Secondary 46B99.

Keywords. Schäffer-type constant, absolute normalized norm, uniform normal structure. 


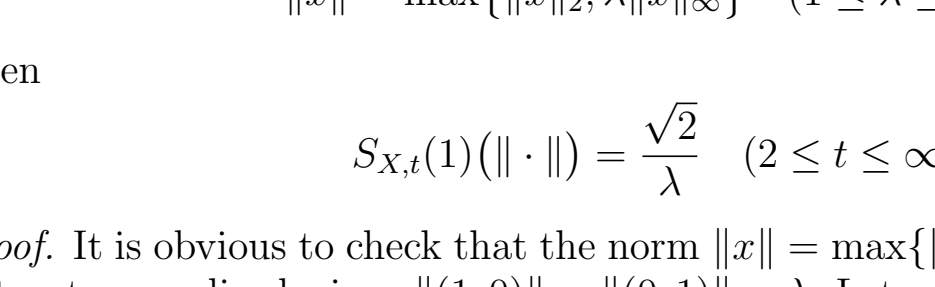

\title{
SCHÄFFER-TYPE CONSTANT AND UNIFORM NORMAL STRUCTURE IN BANACH SPACES
}

\author{
ZHAN-FEI ZUO ${ }^{1,2}$ and CHUN-LEI TANG ${ }^{1 *}$
}

Communicated by P. N. Dowling

\begin{abstract}
The exact value of the Schäffer-type constants are investigated under the absolute normalized norms on $\mathbb{R}^{2}$ by means of their corresponding continuous convex functions on $[0,1]$. Moreover, some sufficient conditions which imply uniform normal structure are presented. These results improve some known results.
\end{abstract}

\section{INTRODUCTION AND PRELIMINARIES}

Throughout this article, $S_{X}$ and $B_{X}$ denote the unit sphere and the unit ball of a Banach space $X$, respectively. Let $C$ be a nonempty bounded closed convex subset of a Banach space $X$. A mapping $T: C \rightarrow C$ is said to be nonexpansive, provided that the inequality

$$
\|T x-T y\| \leq\|x-y\|
$$

holds for every $x, y \in C$. A Banach space $X$ is said to have the fixed point property if every nonexpansive mapping $T: C \rightarrow C$ has a fixed point.

Recall that a Banach space $X$ is called uniformly nonsquare in the sense of Schäffer if there is a $\lambda>1$ such that

$$
\max (\|x+y\|,\|x-y\|) \geq \lambda
$$

for all $x, y \in S_{X}$. The Schäffer constant, defined by

$$
S(X)=\inf \left\{\max \left\{\|x+y\|,\|x-y\|: x, y \in S_{X}\right\}\right\},
$$

Copyright 2016 by the Tusi Mathematical Research Group.

Received Oct. 13, 2015; Accepted Jan. 25, 2016.

${ }^{*}$ Corresponding author.

2010 Mathematics Subject Classification. Primary 46B20; Secondary 46B99.

Keywords. Schäffer-type constant, absolute normalized norm, uniform normal structure. 


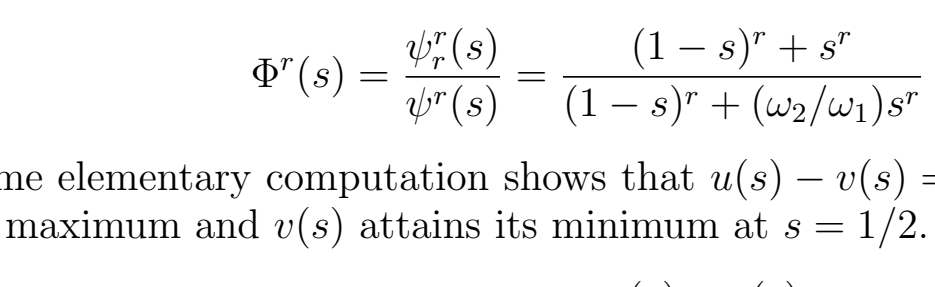

\title{
SCHÄFFER-TYPE CONSTANT AND UNIFORM NORMAL STRUCTURE IN BANACH SPACES
}

\author{
ZHAN-FEI ZUO ${ }^{1,2}$ and CHUN-LEI TANG ${ }^{1 *}$
}

Communicated by P. N. Dowling

\begin{abstract}
The exact value of the Schäffer-type constants are investigated under the absolute normalized norms on $\mathbb{R}^{2}$ by means of their corresponding continuous convex functions on $[0,1]$. Moreover, some sufficient conditions which imply uniform normal structure are presented. These results improve some known results.
\end{abstract}

\section{INTRODUCTION AND PRELIMINARIES}

Throughout this article, $S_{X}$ and $B_{X}$ denote the unit sphere and the unit ball of a Banach space $X$, respectively. Let $C$ be a nonempty bounded closed convex subset of a Banach space $X$. A mapping $T: C \rightarrow C$ is said to be nonexpansive, provided that the inequality

$$
\|T x-T y\| \leq\|x-y\|
$$

holds for every $x, y \in C$. A Banach space $X$ is said to have the fixed point property if every nonexpansive mapping $T: C \rightarrow C$ has a fixed point.

Recall that a Banach space $X$ is called uniformly nonsquare in the sense of Schäffer if there is a $\lambda>1$ such that

$$
\max (\|x+y\|,\|x-y\|) \geq \lambda
$$

for all $x, y \in S_{X}$. The Schäffer constant, defined by

$$
S(X)=\inf \left\{\max \left\{\|x+y\|,\|x-y\|: x, y \in S_{X}\right\}\right\},
$$

Copyright 2016 by the Tusi Mathematical Research Group.

Received Oct. 13, 2015; Accepted Jan. 25, 2016.

${ }^{*}$ Corresponding author.

2010 Mathematics Subject Classification. Primary 46B20; Secondary 46B99.

Keywords. Schäffer-type constant, absolute normalized norm, uniform normal structure. 


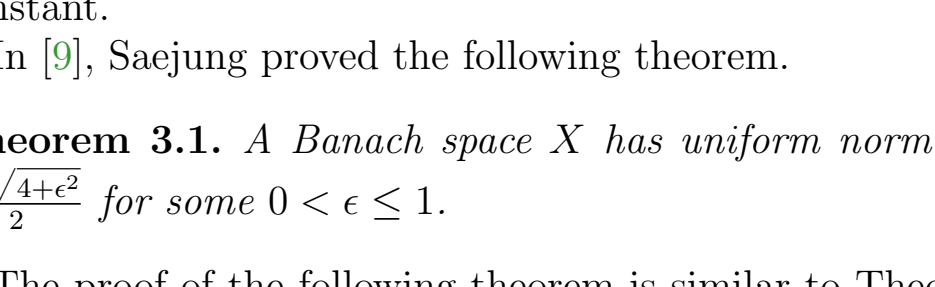

\title{
SCHÄFFER-TYPE CONSTANT AND UNIFORM NORMAL STRUCTURE IN BANACH SPACES
}

\author{
ZHAN-FEI ZUO ${ }^{1,2}$ and CHUN-LEI TANG ${ }^{1 *}$
}

Communicated by P. N. Dowling

\begin{abstract}
The exact value of the Schäffer-type constants are investigated under the absolute normalized norms on $\mathbb{R}^{2}$ by means of their corresponding continuous convex functions on $[0,1]$. Moreover, some sufficient conditions which imply uniform normal structure are presented. These results improve some known results.
\end{abstract}

\section{INTRODUCTION AND PRELIMINARIES}

Throughout this article, $S_{X}$ and $B_{X}$ denote the unit sphere and the unit ball of a Banach space $X$, respectively. Let $C$ be a nonempty bounded closed convex subset of a Banach space $X$. A mapping $T: C \rightarrow C$ is said to be nonexpansive, provided that the inequality

$$
\|T x-T y\| \leq\|x-y\|
$$

holds for every $x, y \in C$. A Banach space $X$ is said to have the fixed point property if every nonexpansive mapping $T: C \rightarrow C$ has a fixed point.

Recall that a Banach space $X$ is called uniformly nonsquare in the sense of Schäffer if there is a $\lambda>1$ such that

$$
\max (\|x+y\|,\|x-y\|) \geq \lambda
$$

for all $x, y \in S_{X}$. The Schäffer constant, defined by

$$
S(X)=\inf \left\{\max \left\{\|x+y\|,\|x-y\|: x, y \in S_{X}\right\}\right\},
$$

Copyright 2016 by the Tusi Mathematical Research Group.

Received Oct. 13, 2015; Accepted Jan. 25, 2016.

${ }^{*}$ Corresponding author.

2010 Mathematics Subject Classification. Primary 46B20; Secondary 46B99.

Keywords. Schäffer-type constant, absolute normalized norm, uniform normal structure. 


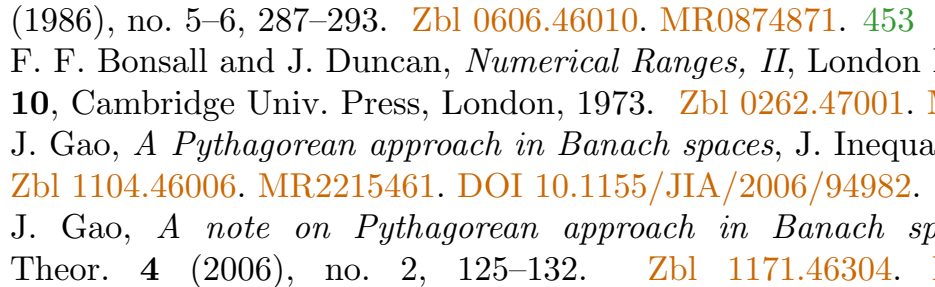

\title{
SCHÄFFER-TYPE CONSTANT AND UNIFORM NORMAL STRUCTURE IN BANACH SPACES
}

\author{
ZHAN-FEI ZUO ${ }^{1,2}$ and CHUN-LEI TANG ${ }^{1 *}$
}

Communicated by P. N. Dowling

\begin{abstract}
The exact value of the Schäffer-type constants are investigated under the absolute normalized norms on $\mathbb{R}^{2}$ by means of their corresponding continuous convex functions on $[0,1]$. Moreover, some sufficient conditions which imply uniform normal structure are presented. These results improve some known results.
\end{abstract}

\section{INTRODUCTION AND PRELIMINARIES}

Throughout this article, $S_{X}$ and $B_{X}$ denote the unit sphere and the unit ball of a Banach space $X$, respectively. Let $C$ be a nonempty bounded closed convex subset of a Banach space $X$. A mapping $T: C \rightarrow C$ is said to be nonexpansive, provided that the inequality

$$
\|T x-T y\| \leq\|x-y\|
$$

holds for every $x, y \in C$. A Banach space $X$ is said to have the fixed point property if every nonexpansive mapping $T: C \rightarrow C$ has a fixed point.

Recall that a Banach space $X$ is called uniformly nonsquare in the sense of Schäffer if there is a $\lambda>1$ such that

$$
\max (\|x+y\|,\|x-y\|) \geq \lambda
$$

for all $x, y \in S_{X}$. The Schäffer constant, defined by

$$
S(X)=\inf \left\{\max \left\{\|x+y\|,\|x-y\|: x, y \in S_{X}\right\}\right\},
$$

Copyright 2016 by the Tusi Mathematical Research Group.

Received Oct. 13, 2015; Accepted Jan. 25, 2016.

${ }^{*}$ Corresponding author.

2010 Mathematics Subject Classification. Primary 46B20; Secondary 46B99.

Keywords. Schäffer-type constant, absolute normalized norm, uniform normal structure. 